\title{
Interaction of $\mathrm{RuO}_{2}$ and Lead-Silicate Glass in Thick-Film Resistors
}

\author{
Gulmurza Abdurakhmanov ${ }^{1}$, Gulbahor S. Vakhidova ${ }^{1}$, Lutfullo X. Tursunov ${ }^{2}$ \\ ${ }^{1}$ Institute of Power Engineering and Automation of the Uzbek Academy of Sciences, Tashkent, Uzbekistan; \\ ${ }^{2}$ FORTEK Private Enterprise, Tashkent, Uzbekistan \\ Email: gulmirzo@mail.ru
}

Received January $4^{\text {th }}, 2011$; revised January $24^{\text {th }}, 2011$; accepted February $1^{\text {st }}, 2011$.

\begin{abstract}
Results of investigation of X-ray diffraction, infrared and optical spectra of powders of the ruthenium dioxide, lead-silicate glass as well as their mixture before and after sintering are reported. Sintering conditions typical for thick film resistors were used. Intensity of main lines of $\mathrm{RuO}_{2}$ in $\mathrm{X}$-ray diffraction patterns of sintered mixtures decreases and they slightly shift towards small angles. No new reflexes appear in these patterns. Absorbance of $\mathrm{RuO}_{2}$ in the range of 2.5-100 $\mu \mathrm{m}$ is proportional to $\lambda^{-1}$ and featureless. Infrared spectrum of lead-silicate glass has absorption bands of $\left[\mathrm{SiO}_{4}\right]^{4-}$ tetrahedra and $\mathrm{Pb}-\mathrm{O}$ bonds only. Optical spectrum of $\mathrm{RuO}_{2}$ has wide absorption bands at 950 and $370 \mathrm{~nm}$. Spectra of the mixture of $\mathrm{RuO}_{2}$ and glass powders before and after sintering are different indicating that there is interaction between them during the sintering process. Concentration of free charge carriers estimated from the optical spectra is about $10^{21} \mathrm{~cm}^{-3}$.
\end{abstract}

Keywords: Ruthenium Dioxide, Lead-Silicate Glass, Thick Film Resistors, Infra Red And Optical Spectra, $X$-Ray Diffraction

\section{Introduction}

Thick film resistors (TFR) are complex heterophase systems [1-7] having the following characteristic inhomogeneity scales:

1) large scale inhomogeneity of few $\mu \mathrm{m}$ or larger, due to substrate, terminations and surface of sample;

2) middle scale inhomogeneity of 0.1 to few $\mu \mathrm{m}$ in size as result of mixing and sintering of powders of glass and conductive phase (CP);

3 ) nanoscale inhomogeneity of $1-2 \mathrm{~nm}$ is a characteristic of the glass itself.

Large scale inhomogeneities are dependent on the design of TFR mainly and too a much lesser extent on its volume. Investigation of nanoscale inhomogeneities is extremely difficult. Moreover the existence of them in glass is the subject of the discussions up to date. So these two kinds of inhomogeneities are usually not considered the factors affecting the conduction mechanism of TFR.

Middle scale inhomogeneity is observed in electron microphotography and in X-ray diffraction patterns of TFR and was the basis to consider the conduction of TFR to be the percolation process. All of the researchers consider the infinite conductive cluster as formed by direct- contact of the particles of conductive phase, and glass to be a passive matrix to fix the particles. But this approach does not explain the properties of TFR such as the effect of glass composition, kind of CP and the effect of sintering conditions on the value of conductivity $\sigma$ of TFR and the percolation threshold. In addition, the percolation threshold on the $\sigma(C)$ might disappear for TFR made of glass of some compositions. There $C$ is volume content of CP. These facts point to the interaction of CP and glass during the sintering process and this interaction is diffusion.

Profiles of diffusion of $\mathrm{RuO}_{2}$ into glass were measured in earlier works [8,9] via electron microprobe. In particular, formation of the reactive layer around $\mathrm{RuO}_{2}$ particles is considered in [8]. Measurements of the resistivity across the interface of glass - $\mathrm{RuO}_{2}$ (angle lap method) have shown that diffusion length of $\mathrm{Ru}$ into the lead-boron-silicate glass is $0.5-2 \mathrm{um}$ at $1123 \mathrm{~K}$ in 10 $\min$.

In [9] diffusion is used to explain effect of sintering conditions (peak temperature and duration) on frequency dependence of impedance of TFR. Thickness of diffusion layer is estimated as few tenths of um at $900 \mathrm{~K}$ in 30 
minutes and diffusion profile considered to be an error function.

The effect of the thickness of TFR on electrical properties is explained in [10] in terms of diffusion.

Conductivity of TFR as a function of sintering temperature $T_{\mathrm{f}}$ was measured in [11] and it has been shown that percolation levels form due to diffusion of atoms of $\mathrm{CP}$ into the glass. The parameters of the diffusion process were estimated from these experiments. The values of activation energy of diffusion (0.2-1.08 eV) in TFR obtained in [11] are not large and so one can assume diffusion to be of exchange type (exchange of oxygen bonds with lead and ruthenium atoms).

But this method is indirect and is based on the properties of electron subsystem in TFR only. It must be noted that there are no visible thermal effects on differential thermal analysis (DTA) curves of the mixture of CP and glass powders at $T>900 \mathrm{~K}$. This fact points at the diffusion and not at the generation of new chemical compounds.

Here we report results of our investigation of interaction of glass and CP (namely $\mathrm{RuO}_{2}$ was used more often) via optical and infrared (IR) spectra since these methods are sensitive to the variations in both electron subsystem and bonds of atoms. X-ray diffraction (XRD) has been used as well.

\section{Experiment}

Samples investigated were powders of $\mathrm{RuO}_{2}$, leadsilicate glass $2 \mathrm{SiO}_{2} \cdot \mathrm{PbO}$, mixture of them before and after sintering in conditions standard for TFR technology (peak temperature $T_{\mathrm{f}}=1123 \mathrm{~K}$, duration of sintering at peak temperature $\tau=10$ minute, total duration $60 \mathrm{~min}$ ute). Powder particles were $0.2 \mu \mathrm{m}$ and $0.5 \mu \mathrm{m}$ in diameter for glass and $\mathrm{RuO}_{2}$ correspondingly. Sintered mixture was milled up to $0.5 \mu \mathrm{m}$ particle size too. Components used for glass melting were of technical category.

$\mathrm{RuO}_{2}$ powders were made by thermal decomposition of $\mathrm{Ru}(\mathrm{OH}) \mathrm{Cl}_{3}$ in air at $1100 \mathrm{~K}$, milled and calcined at the same temperature for 1 hour. There were no extraneous compounds of significant amounts found in the powder via XRD. Average size of particles in the powder was about $250 \AA$ from Sherrer formula, while the specific surface measurements give average size of about 0.5 $\mu \mathrm{m}$. Therefore, one can assume the particles of powder investigated to be polycrystalline consisting from large number of crystalline regions oriented randomly. The discrepancy arises from gist of these methods. The Sherrer's formula gives main size of the region of coherent scattering (i.e. single crystalline region). On the contrary specific surface measurements give average open surface of the particles, from which main size of them will be calculated regardless of its internal structure (single crystal, polycrystalline etc.) so last value is always no smaller than first one.

IR absorption spectra of powders were taken on the IFS-113 Bruker Fourier spectrometer in the range of 2.5-100 $\mu \mathrm{m}$, optical spectra - on the Specord M-40 (Karl Zeis, Jena) spectrometer in the $330-1050 \mathrm{~nm}$ range.

XRD patterns were taken on diffractometer DRON$\mathrm{UM}-01$ on $\mathrm{CuK} \alpha$ radiation with graphite monochromator on reflected beam.

\section{Results and Discussion}

IR and optical absorption spectra of glass, $\mathrm{RuO}_{2}$, mixture of them before and after sintering are shown in Figures 1 and 2. One can see the fine structure (minute fluctuations) on optical spectra (Figure 2) caused by submicron size of powder particles [12].

Absorption bands near $10 \mu \mathrm{m}$ and $22 \mu \mathrm{m}$ on the IR spectrum of glass powder (Figure 1, curve 1) are due to vibrations of $\left[\mathrm{SiO}_{4}\right]^{4-}$ tetrahedra and $\mathrm{Pb}-\mathrm{O}$ bonds $[13,14]$.

IR absorption spectrum of $\mathrm{RuO}_{2}$ is featureless and absorbance is varied as $\lambda^{-1}$ (Figure 1, curve 2). This means that atomic absorption is suppressed by that of free charge carriers, and $\omega<\omega_{p}$, where

$$
\omega_{p}=\left(n e^{2} / m^{*} \varepsilon_{0}\right)^{1 / 2}
$$

is plasma angular frequency, $n$ and $m^{*}$ are concentration and effective mass of free carriers, $\varepsilon_{0}$ is the permittivity of vacuum [15].

IR spectrum of mixture of glass and $\mathrm{RuO}_{2}$ powders before sintering is superposition of appropriate spectra (Figure 1, curve 3) and do not have new absorption bands. The character of the spectra changes after sintering (Figure 1, curve 4): absorption increases at $\lambda>10$ $\mu \mathrm{m}$ and the wavelength dependence is stronger, new absorption bands appear at $6.6 \mu \mathrm{m}$ and $12.5 \mu \mathrm{m}$. The latter one overlaps with the long-wavelength wing of intensive band at $10 \mu \mathrm{m}$. Absorption by free carriers is still dominant in the region of $\lambda<9 \mu \mathrm{m}$ and $\alpha \sim \lambda^{-1}$.

Optical spectrum of glass powder (Figure 2, curve 1)

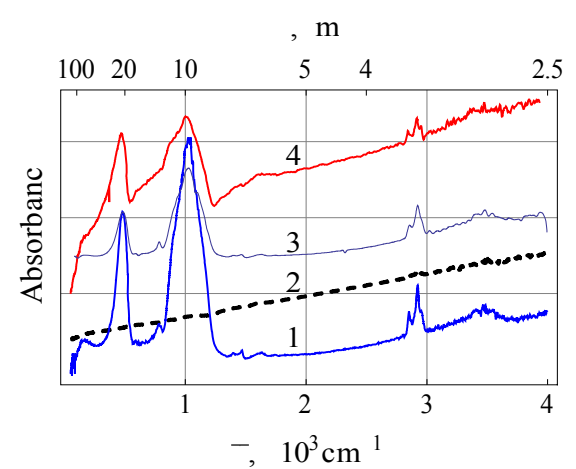

Figure 1. IR spectra of powders: glass (1), $\mathrm{RuO}_{2}(2)$, mixture of them before (3) and after (4) sintering. 


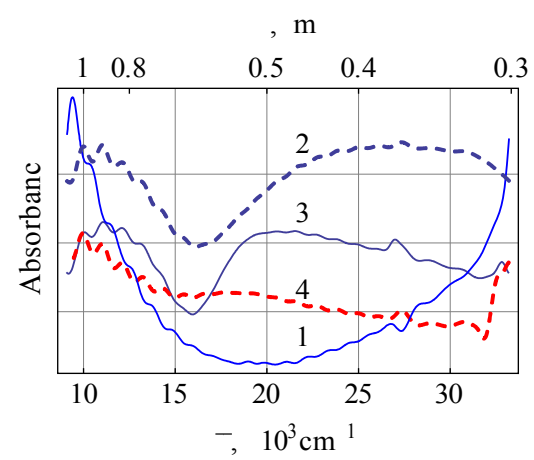

Figure 2. Optical spectra of powders. Notations see Figure 1.

is typical and shows the fundamental absorption band starting at $350 \mathrm{~nm}$ (transitions from valence band to conductive band) inherent to glass containing $33 \mathrm{~mol} . \%$ of $\mathrm{PbO}[16]$.

Optical spectrum of $\mathrm{RuO}_{2}$ powder (Figure 2, curve 2) has two wide absorption bands centered at 360 and 950 $\mathrm{nm}$ (location of last one is approximated because of existence of fine structure).

Optical spectrum of the mixture of powders before sintering (Figure 2, curve 3), like the IR spectrum, is the superposition of spectra of initial powders and does not have additional peculiarities.

The absorption band at $950 \mathrm{~nm}$ of optical spectrum of sintered mixture (Figure 2, curve 4) is slightly shifted to highest wavelength and band at $360 \mathrm{~nm}$ almost disappears.

It should be noted that in contrast to single crystals, the powders of $\mathrm{RuO}_{2}$ used by us are semiconducting (Figure 3). This might be due to the oxygen excess on the surface of particles. These measurements were made on pellets pressed at $800 \mathrm{MPa}$, when resistivity becomes nearly independent on applied press. Activation energy determined as a slope of $\sigma(T)$, has two values: 0.45 and 0.025 $\mathrm{eV}$. Higher value could be attributed to the oxygen layer on the surface of particles which makes them semiconductive, and smaller value is the property of the particle volume.

So one can relate the band $360 \mathrm{~nm}$ to the surface layer (transitions between $\mathrm{Ru} 5 \mathrm{~s}$ and $\mathrm{O} 3 \mathrm{~s}$ states with transition energy of $\sim 3 \mathrm{eV}$ ) and band $950 \mathrm{~nm}$ - to plasma resonance of free carriers. Thus, it follows from (1) that $n$ has decreased from $1.2 \cdot 10^{21} \mathrm{~cm}^{-3}$ to $1.1 \cdot 10^{21} \mathrm{~cm}^{-3}$ due to sintering.

Gas of free carriers of same concentration is degenerated and temperature dependence of the resistivity of TFR follows the power-law $\left(\rho \sim T^{k}\right)$ in accordance with scattering mechanism.

Density of $\mathrm{RuO}_{2}$ molecules is $3.6 \cdot 10^{22} \mathrm{~cm}^{-3}$ and there is only one electron per 30 atoms of $\mathrm{Ru}$ (see above) in

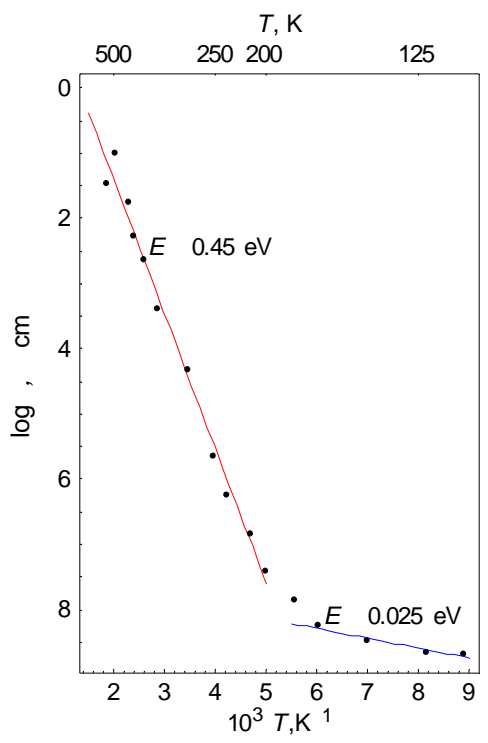

Figure 3. $\sigma(T)$ of $\mathrm{RuO}_{2}$ pallets.

$\mathrm{RuO}_{2}$ powder at room temperature. On the other hand one can assume that all $\mathrm{Ru}$ atoms diffused into glass are ionized and concentration of free carriers in TFR is equal to that of $\mathrm{Ru}$ atoms. Intensity of the main lines of X-ray diffraction of $\mathrm{RuO}_{2}$ in mixture of glass and $\mathrm{RuO}_{2}$

powders after firing decreases up to $90 \%$ of that in the nonfired mixture. Since volume content of $\mathrm{RuO}_{2}$ in mixture was $16 \%$ (corresponds to 25 weight \%) one can consider that only small part of Ru atoms (nearly $3 \%$ ) is diffused from particles into glass.

Paucity of $\mathrm{Ru}$ atoms diffused into glass is verified from X-ray diffraction patterns as well (Figure 4). Main reflexes of $\mathrm{RuO}_{2}$ in last one are broadened and shifted slightly to small angle after sintering. This means that the relicts of $\mathrm{RuO}_{2}$ crystals are stressed in TFR because of the highest value of thermal expansion coefficient of $\mathrm{RuO}_{2}$ crystals in the $a$ direction in comparison to that of glass $\left(144 \cdot 10^{-7} \mathrm{~K}^{-1}\right.$ and $71 \cdot 10^{-7} \mathrm{~K}^{-1}$ accordingly), while in the $c$ direction it is negative $\left(-39 \cdot 10^{-7} \mathrm{~K}^{-1}\right)$.

New bonds O-Ru-O form during the sintering process in addition to the existing $\mathrm{Si}-\mathrm{O}-\mathrm{Si}$ bonds (bridge atoms of oxygen) and $\mathrm{O}-\mathrm{Pb}-\mathrm{O}$, inherent in glass $2 \mathrm{SiO}_{2} \cdot \mathrm{PbO}$. Additional bonds have large dispersion of length and bonding constant because the diffused atoms of $\mathrm{Ru}$ became bonded both to the $\left[\mathrm{SiO}_{4}\right]^{4-}$ tetrahedra and $\mathrm{Pb}$ atoms, generating the Si-O-Ru-O-Si, Si-O-Ru-O-Pb-O and $\mathrm{O}-\mathrm{Pb}-\mathrm{O}-\mathrm{Ru}-\mathrm{O}-\mathrm{Pb}$ bonds. Retained bonds $\mathrm{O}-\mathrm{Ru}-\mathrm{O}-\mathrm{Ru}-\mathrm{O}$ are deformed due to the mismatch of thermal expansion of $\mathrm{RuO}_{2}$ and glass. Since the atomic mass of $\mathrm{Ru}$ atom lays between that of $\mathrm{Si}$ and $\mathrm{Pb}$, the bonds of $\mathrm{Ru}$ with oxygen atoms, having different location in glass structure, appear as wide absorption band between 10 and $22 \mu \mathrm{m}$ (Figure 1). 


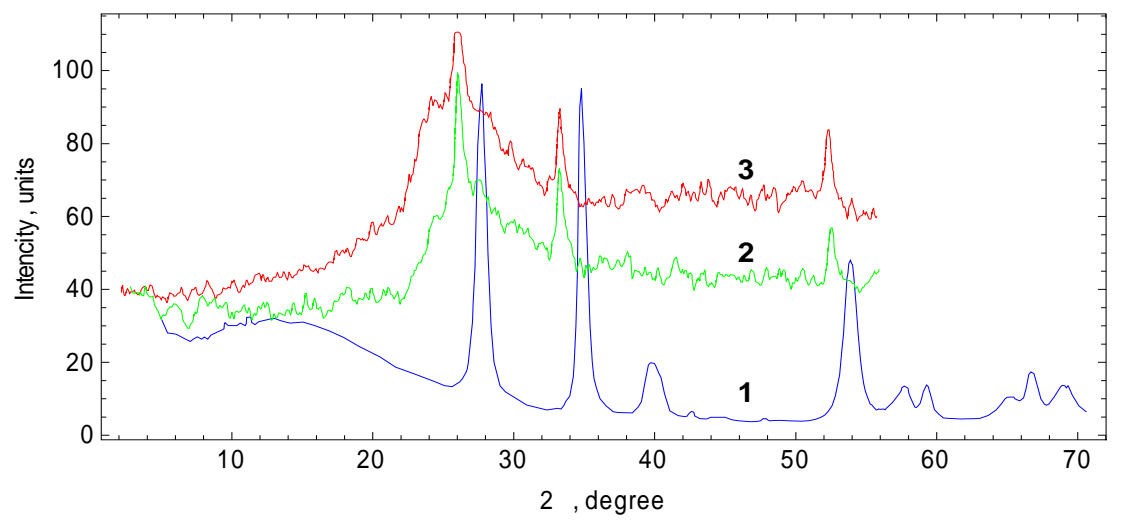

Figure 4. X-ray diffraction in $\mathrm{RuO}_{2}(1)$ and $\mathrm{TFR}$ (glass + 16 mass. \% $\mathrm{RuO}_{2}$ ), sintered at $873 \mathrm{~K}(2)$ and at $1073 \mathrm{~K}(3)$.

\section{Conclusions}

Sintering of the TFR consisting from $\mathrm{RuO}_{2}$ and silicate glass leads to interaction of them. But no new reflexes of reasonable intensity were observed in XRD and one can exclude the formation of new chemical compounds and consider the interdiffusion of components. As a result of diffusion the glass becomes conductive and infinite conductive cluster is formed from adjacent diffusion zones centered on the CP particles. Because of them percolation threshold can shift to small content of CP or disappear if diffusion process is long enough. Exclusion of the interaction of CP and glass in TFR might be the main obstacles in attempts to explain the electrical properties of TFR.

It is clear from the IR spectra of glass powders, CP and their mixture that free charge carriers are the main factor of absorption and have so high concentration that the frequency of plasma resonance is shifted to the optical range. Free carriers concentration estimated from optical spectra is about $10^{21} \mathrm{~cm}^{-3}$ and gas of them is degenerated. Small value of activation energy of diffusion (0,2-1,08 eV) calculated from electrical measurements [11] shows that diffusion is of the exchange type (exchange of oxygen bonds with $\mathrm{Pb}$ and $\mathrm{Ru}$ atoms).

\section{Acknowledgements}

Fond for Support of Fundamental Researches of the Uzbek Academy of Sciences is acknowledged for the financial support (grants 55-08 and 27-10).

\section{REFERENCES}

[1] G. E. Pike and C. H. Seager, "Electrical Properties and Conduction Mechanisms of Ru-Based Thick-Film (Cermet) Resistors," The Journal of Applied Physics, Vol. 48, No. 12, 1977, pp. 5152-5169.

[2] D. P. H. Smith and J. C. Anderson, "Electron Conduction in Thick Film Resistors," Thin Solid Films, Vol. 71, 1980, pp. 79-89.

[3] A. Cattaneo and M. Prudenziati, "Effects of Refiring Processes on Electrical and Structural Properties of Thick-Film Resistors," Electrocomponent Science and Technology, Vol. 6, No. 3-4, 1980, pp. 165-171.

[4] B. Morten, A. Masoero, M. Prudenziati and T. Manfredini, "Evolution of Ruthen-Ate-Based Thick Film Cermet Resistors," Journal of Physics D: Applied Physics, Vol. 27, 1994, 2227.

[5] Johnson F., Crosbie G. M. and Donlon W. T. The effect of processing conditions on the resistivity and microstructure of ruthenate-based thick film resistors // J. Materials Science: Mat. In Electronics 8 (1997) 29.

[6] Meneghini C., Mobilio S., Pivetti F., Selmi I., Prudenziati M. and Morten $\mathrm{B}$. $\mathrm{RuO}_{2}$-based thick film resistors studied by extended x-ray absorption spectros-copy // J. Appl. Phys. 86 (1999) 3590.

[7] Gabáni S., Flachbart K., Pavlík V., Pietriková A. and Gabániová M. Micro-structural Analysis and Transport Properties of $\mathrm{RuO}_{2}$-Based Thick Film Resistors // Acta Physica Polonica A 113 (2008) No. 1, 625.

[8] Abe A. and Taketa Y. Electrical conduction in thick film resistors // J. Appl. Phys. 24 (1991) 1163.

[9] Koo B. K., No K. S. and Kim H. G. AC complex impedance investigation for $\mathrm{RuO}_{2}$-glass composites // IEEE Trans. CHMT-14, \#3 (1991) 580.

[10] Zheng Y., Atkinson J. and Sion R. An explanation of thermal behaviour of thick film strain gauges // J. Phys. D: Appl. Phys. 36 (2003) 1153.

[11] Abdurakhmanov G., Vakhidova G. S. Diffusion and electrical conduction in thick film resistors // Technical Physics. The Russian Journal of Applied Physics 65 (1995), \#7, 178.

[12] Born M., Volf E. Principles of optics, Cambridge, Cambridge University Press, 2005. - 986 pp.

[13] Infrakrasnie spektri neorganicheskix stekol I kristallov (Infrared spectra of inorganic glasses and crystals) (in Russian) / Vlasov A. G., Florinskaya V. A. et al. - Leningrad, Ximiya Publishing House, 1972. - 304 pp. 
[14] Lazarev A. N. Kolebatelnie spektri I stroenie silikatov (Vibrational spectra and structure of silicates) (in Russian). Leningrad, Nauka Publishing House, 1968.- 348 pp.

[15] Ginzburg V. L. The propagation of electromagnetic waves in plasmas. Transl. from russian. Oxford, New
York, Pergamon Press, 1970. - 615 p.

[16] Sidorov T. A. Infrakrasnie I ultrafioletovie spektri I structura svintsovo-silikatnix stekol (Infrared and ultravio-let spectra and structure of lead-silicate glasses) (in Russian) // J. Prikladnoy Spektroskopii (J. Appl. Spectroscopy) 6 (1967) 98. 